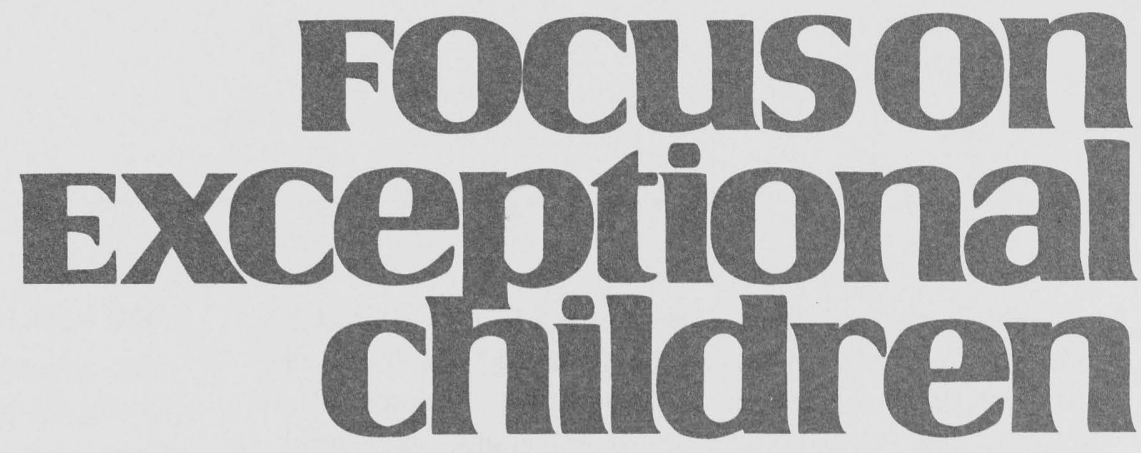

\title{
Discipline in Special Education and General Education Settings
}

\section{Deborah Deutsch Smith and Diane Pedrotty Rivera}

Discipline is of utmost concern to educators and is viewed by the American public as a major problem in education (Gallup, 1984, 1994). State legislators and Congress also view it as a major problem in our nation's schools — one that must be solved. Many reasons are cited for the lack of discipline in school settings: for example, low teacher salaries, insufficient funding for education, lack of parental support, and a disregard for authority by students. Many of these problems are beyond the control of educators but must not be used as an excuse for why discipline problems cannot be ameliorated. Rather, educators must focus on identifying and addressing the individual needs of students, improving the educational environment, using effective prevention and intervention techniques, and building collaborative partnerships.

Although the majority of students do not present discipline problems, even a small number of students who engage in negative behavior can disrupt the learning environment and divert teacher time from instruction to manage the situation. Therefore, educators must establish a system of order that clearly defines the boundaries for acceptable behavior and provides consequences for appropriate and inappropriate behavior.

Discipline can be defined as “. . . order among pupils so learning can take place without competition from unproductive factors. It is a system of rules for conduct and a mechanism for ensuring that conduct codes are followed" (Smith \& Rivera, 1993, p. 2). A system of classroom order can be achieved when principles of effective discipline are implemented:

1. Establish a positive climate.

2. Build a foundation for a positive learning environment.

3. Use prevention techniques.

4. Establish collaborative relationships with parents and other professionals for dealing with discipline concerns and promoting a positive learning climate.

5. Match intervention to behavior problem.

6. Establish an evaluation system to monitor student progress frequently.

When these principles are incorporated into educators' instructional repertoires, an environment for success and learning can be fostered and more time can be devoted to teaching. Providing a learning environment based on the principles of effective discipline can help students understand the relationship between specific behaviors and their consequences and can result in all students learning important social skills.

Deborah Smith is a professor and the director of the Alliance 2000 Project at the University of New Mexico. $\mathrm{Di}$ ane Rivera is an assistant professor of special education at the University of Texas at Austin. 
Today's educators must consider many factors when planning their discipline programs (for example, students' cultural and linguistic diversity or disabilities). Educators from various fields (special education, general education, counseling, remedial reading) must work collaboratively to accommodate the needs of all students. As students with disabilities spend more of their school day in the general education setting, special education and general education professionals must develop discipline plans collaboratively. General education teachers need to be comfortable with the needs of students with disabilities as they implement their discipline programs. The purpose of this article is to present what we believe are the components of an effective discipline program. We begin by providing possible reasons for discipline problems, followed by a discussion of prevention and intervention techniques. We conclude by explaining some techniques for evaluating discipline programs.

\section{Focuson
Exceptional
children}

ISSN 0015-511X

FOCUS ON EXCEPTIONAL CHILDREN (USPS 203-360) is published monthly except June, July, and August as a service to teachers, special educators, curriculum specialists, administrators, and those concerned with the special education of exceptional children. This publication is annotated and indexed by the ERIC Clearinghouse on Handicapped and Gifted Children for publication in the monthly Current Index to Journals in Education (CIJE) and the quarterly index, Exceptional Children Education Resources (ECER). The full text of Focus on Exceptional Children is also available in the electronic versions of the Education Index. It is also available in microfilm from Xerox University Microfilms, Ann Arbor, MI. Subscription rates: Individual, $\$ 30$ per year; institutions, $\$ 40$ per year. Copyright (C) 1995 , Love Publishing Company. All rights reserved. Reproduction in whole or part without written permission is prohibited. Printed in the United States of America. Second class postage is paid at Denver, Colorado. POSTMASTER: Send address changes to:

Love Publishing Company

Executive and Editorial Office

1777 South Bellaire Street

Denver, Colorado 80222

Telephone (303) 757-2579

Edward L. Meyen

University of Kansas

Glenn A. Vergason Georgia State University

Richard J. Whelan

University of Kansas Medical Center

Stanley F. Love Publisher

Holly T. Rumpler Senior Editor

\section{WHY DISCIPLINE PROBLEMS OCCUR}

Just as students come to America's public schools with a great variety of learning styles and needs, some have a variety of reasons for not conforming to school rules and expectations. A few of those are briefly discussed in the following sections.

\section{Types of Disruptions}

Almost all students exhibit some kind of discipline problem or disruptive behavior during their 13-year school career. It is the kind, degree, place, and amount of disruption that determine whether the behavior requires a comprehensive discipline plan. Often there is a fine line between what is acceptable deportment and what is not, and many students have difficulty understanding where the line falls and what behavior crosses it (Krumboltz \& Krumboltz, 1972). In many cases, school personnel need to help students understand the subtle discriminations required to meet the behavioral demands of the various educational settings they experience. Students need to learn when it is appropriate to talk in class and when it is not. They must learn which teachers tolerate a noisy class and which do not. Educators must help students learn to discriminate between the behavioral demands of each school situation and match that situation with the proper behavior pattern. Effectively matching the situation with the appropriate behavior pattern is an important skill to learn. In other words, some conduct problems occur simply because students do not know how to read the environmental cues-some subtle and some not so subtle - that indicate the acceptability of behavior.

\section{Circumstances}

Sometimes conduct problems occur because teachers' expectations are unrealistic. For example, expecting a class of first-graders to sit quietly for a symphony orchestra's hourlong rehearsal is probably unreasonable, as it is unreasonable to expect bright students to sit and wait 20 minutes for the rest of the class to complete a seatwork assignment. Teachers who judge the attention span of their students will help avoid conduct difficulties.

The arrangement of the environment should also be considered. Sometimes behavior problems occur because traffic patterns are congested or seating arrangements are poorly arranged. Simply observing how students interact socially can help teachers decide what might be appropriate seating arrangements.

Transitional times also can invite disruption. When students are free to move about the classroom from one activity 
to the next, change from one lesson to another, or freely line up to go from the classroom to another area without supervision or clear rules or expectations; the result is often confusion and disruption.

\section{Instructional Procedures}

Effective instructional procedures include practices that minimize behavioral problems. For example, when students are left to complete work independently when they are not equipped to do so, the environment is open for disruption. Sometimes students are disruptive because they don't understand what is being taught and fail to ask questions for clarification. For other students the lesson may move too slowly, allowing students time to create diversions to occupy their attention until the teacher is ready to move on to the next activity.

\section{Boredom or Frustration}

Many behavioral problems occur because students are either bored with an activity that is too easy or frustrated because it is too difficult. One important study (Center, Deitz, \& Kaufman, 1982) evaluated the relationship between task difficulty and inappropriate behavior. The relationship is dramatic and clear. When there is a mismatch between student ability and academic assignments, disruption occurs at a high level. The need for flexible educational programming is a pervasive reality in today's schools because of federal requirements to include students with disabilities, to bus pupils to achieve social integration, and not to track or group students by ability. Because of these mandates, teachers must now accommodate students with an increasingly wider range of abilities and plan flexible activities that will hold the interest of diverse class members.

\section{Motivation}

Admittedly, many students come to school with a well-developed ability to disrupt the learning atmosphere. These students know how to read the environmental cues and determine what the behavioral expectations are in various school settings. They are neither bored nor frustrated. For whatever reasons, they are not motivated to become active participants in the learning situation and instead seek to disrupt the learning climate. Their behavioral repertoires are counterproductive to their own and their classmates' learning. Because even one student can destroy the learning environment for an entire class, behavior problems must be confronted. Although many preventive measures are sufficient to encourage most students to behave appropriately, many students are candidates for more direct intervention procedures.

\section{Students with Behavioral Disabilities}

Some students are the source of considerable disruption. Many of these students have disabilities and are included in regular classes. They seem unable to meet the behavioral expectations of typical classroom situations for extended periods of time. Their inability to conform, their frequent frustration over learning activities, and the recognition by their peers that they are different often lead to disruptive situations. Although many of these students need a considerable amount of structure to meet setting demands, they are integrated during parts of the school day when the structure is at a minimum. This may contribute to their difficulties in meeting behavioral expectations. They also are easy targets for teasing and rebuff by general education students, which often leads to further disruptive occurrences. When these students are the center of disruption, there are generally two basic reasons for the disturbance: their inability to act appropriately and their nondisabled counterparts' temptation to bait, chide, and encourage inappropriate behavior from these students. An analysis to determine the causes of inappropriate school behaviors can help educators select specific preventive and intervention measures aimed at reducing disruption.

\section{PREVENTION TECHNIQUES}

Successful discipline plans are based on a foundation of prevention. These techniques require teachers to be familiar with the strengths and weaknesses of their students, curriculum, instruction, and classroom management. Prevention techniques establish the foundation on which teachers can implement additional interventions and promote a positive classroom environment. Several prevention techniques are highlighted for consideration, along with some guiding principles that foster effective discipline programs.

\section{Rules}

Students must be aware of the teacher's expectations of acceptable and unacceptable conduct. These expectations typically are addressed through the use of classroom rules - an important prevention technique because they provide parameters of acceptable behavior. Without rules students are left on their own to devise guidelines for establishing predictability and a sense of security in their environment (Windell, 1991). Most students follow the rules; however, teachers 
should schedule classroom time for the discussion, implementation, and enforcement of the rules if they are to be an effective part in the discipline plan.

Specific suggestions for establishing and implementing rules are provided by Smith and Rivera (1993):

1. Establish a list of rules. Keep the list short and positive (e.g., instead of "No talking," try "Raise your hand to speak"). Be sure the rules can be enforced, are age-appropriate, and are general enough to encompass several behaviors.

2. Involve students in developing the classroom rules. Students can assist in establishing classroom rules at the beginning of the school year and as the need arises. Students can discuss their classroom environment and how specific rules can create a positive climate for learning.

3. Promote student understanding of the rules. Ensure that students understand teachers' expectations by stating the rules, providing specific examples of following and breaking the rules, and practicing the application of the rules. Intermittently praise students who follow the rules, and implement consequences for those who break the rules.

4. Provide students with reminders about the classroom rules. Several occasions may arise that warrant reminders about proper classroom conduct. For example, when rules are first initiated, students may need cues and warnings. Pairing reminders with specific praise is a good strategy to teach the rules. At times of high probability of rule violations, reminders may prevent problems from occurring.

\section{Manage the Environment}

The classroom environment can play a major role in the management of student behavior and the prevention of discipline problems. Teachers who are well prepared and cognizant of student interactions within the environment can create a physical environment and implement management techniques that promote discipline. For instance, high traffic areas are good opportunities for disruptive behavior to occur. Students can talk to each other, initiate physical contact, and be disruptive just in the course of sharpening a pencil or walking to their desks. To prevent such problems, teachers can (a) observe traffic patterns and determine high frequency areas that could be problematic, (b) keep work areas separated to minimize excessive student movement, (c) provide plenty of space, and (d) ensure that areas have easy access (Evertson, Emmer, Clements, Sanford, \& Worsham, 1984).

Teachers can also better manage student learning by organizing the materials to be used by students or teachers during instruction. Classroom organization also promotes more engaged instructional time, minimizes "down time," and increases opportunities for students to initiate appropriate behavior.

\section{Plan for Transitions}

Transitions between lessons and activities or physical environments can be successful or disastrous. The key to effective transitions, and thus appropriate conduct, is planning. Several steps can ensure smooth transitions. For instance, teachers can provide a readiness signal so students know it is time to finish their activity. "In 10 minutes we will go to lunch" is an example of a signal that prepares students for the upcoming transition. A second step is for teachers to tell students how the transition will be made (e.g., line up by rows or students with last names beginning with $\mathrm{M}$ through $\mathrm{Z}$ ) and what behavior is expected (e.g., no talking, have all materials ready). Finally, teachers should provide reinforcement for students who conduct themselves appropriately during transitions.

\section{Guiding Principles}

Some basic principles help establish effective discipline practices. Although many of these principles have been noted in the discipline and behavior management literature for years, they warrant mention because of their effectiveness. The principles include (a) "with-it-ness" or "eyes in the back of your head" technique, (b) "ripple effect" (Kounin, 1970), (c) avoidance of power struggles, (d) avoidance of grudges, (e) focus on student's behavior, not on their character, (f) preparation to teach, $(\mathrm{g})$ anticipation of problems, and $(\mathrm{h})$ implementation of stress management techniques.

\section{INTERVENTION TECHNIQUES}

Discipline problems often occur or continue to occur even though teachers have implemented preventive measures as part of the overall discipline plan and system of order in the classroom. Teachers should address disruptions of classroom rules directly and shape and encourage an instructional environment conducive to learning. There are many ways of achieving discipline and reducing or eliminating behavior problems. For example, mild and positive forms of intervention can be used when preventive measures have proven unsuccessful. The use of severe and negative measures should be kept to a minimum to avoid a serious long-term impact on the climate of the school, overuse of punitive techniques, and the perception that the one who administers the negative procedure is a punitive person. 
The most important technique for promoting a climate for learning is to match the disciplinary infraction with the intervention. To do this, educators must be fully aware of many different intervention techniques and intervene systematically and sensibly. The Intervention Ladder (see Figure 1) graphically depicts a hierarchy of disciplinary interventions that can be used as a guide for selecting an appropriate disciplinary action. The interventions are arranged in a hierarchy from mild to intrusive interventions. Tactics that are found lower on the ladder should be selected first because they tend to remediate a large number of behavioral problems. Those interventions on the higher rungs are more intrusive and should be reserved for use only when other tactics have not been successful. Table 1 presents a definition and an example of each intervention on the ladder.

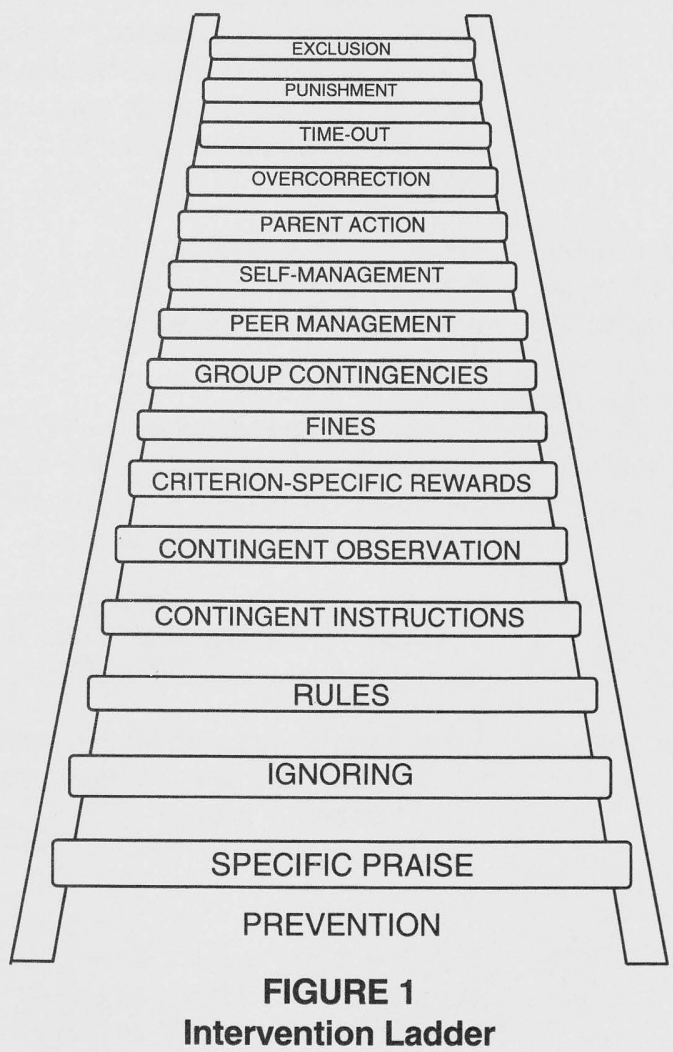

Source: From Effective Discipline (p. 17) by D. D. Smith and D. M. Rivera, 1993, Austin, TX: PRO-ED.

Prevention is the foundation of the ladder and consists of the techniques discussed in previous sections. Sometimes, however, preventive measures are not applied soon enough to avoid the development of discipline problems. If direct intervention becomes necessary, educators should select techniques that reflect a sensitive match between infractions and the intervention procedures. We selected several intervention techniques from the Intervention Ladder in Figure 1 that have been used effectively to manage an individual's or group's behavior in both general and special education settings to discuss here as illustrative examples.

\section{Specific Praise}

Specific praise means giving students positive feedback about their appropriate behavior. It is specific in the sense that students are told which behaviors they engaged in that were appropriate and they are praised for those actions as well. The following examples illustrate both the correct and incorrect applications of specific praise.

The secondary teacher tells a student privately, "Samantha, I appreciate your coming to class on time and bringing all of your books." This statement tells the student specifically what she has done that meets the teacher's expectations.

Brian was able to read quietly for one-half hour without disturbing his neighbors. The teacher commented to Brian, "I appreciate how quietly you have been reading without talking to your neighbors this afternoon."

Mrs. Dodger, the second grade teacher, thanked Alexandra, Mikayla, and Samuel for coming to the reading table for instruction the first time she called them.

"Brett, you certainly did well today" is not specific. A comment such as "Brett, thanks for remembering to raise your hand when you wanted to speak" is specific to the expected performance.

Specific praise is easy to use and when used correctly has a powerful effect on behavior. It can be provided in writing or verbally, publicly or privately, depending on the student who is being praised. At first, specific praise should be used each time the targeted behavior occurs; later, as the student learns the desired behavior, it should be intermittently delivered.

Specific praise can serve both an instructional and reinforcing role. For example, the specific feedback students receive about their positive performance tells them what behavior is expected and desired. This is important for those students who do not fully understand what is expected of them because they have not completely mastered the unspoken rules of conduct. Also, the student is given attention and positive comments about the desired or expected behavior, 
TABLE 1

Glossary for the Intervention Ladder

\begin{tabular}{ll}
\hline Tactic & Definition \\
\hline SPECIFIC PRAISE & $\begin{array}{l}\text { Providing students with positive state- } \\
\text { ments and feedback about their appropri- } \\
\text { ate conduct. }\end{array}$
\end{tabular}

\section{IGNORING}

RULES

CONTINGENT INSTRUCTIONS

CONTINGENT OBSERVATION

\section{CRITERION-SPECIFIC REWARDS}

FINES

\section{GROUP CONTINGENCIES}

Dependent

Independent

Interdependent
Systematically and consistently not paying attention to each occurrence of the target behavior.

The entire class (teacher and pupils) determines a code of conduct for all to follow.

After an occurrence of the target behavior, the teacher quietly and on a one-toone basis tells the individual specifically not to engage in that activity.

Removal of a disruptive student from a group activity, but still allowing the individual to observe the proceedings.

The student earns a special privilege only for reaching the desired behavior.

The student loses privileges for engaging in the target behavior.

A person earns privileges or rewards by behaving appropriately.

Individuals earn reinforcement when they achieve a goal established for the group.

The class or group earns a special reward when the entire class meets the established goal.

\section{Example}

"Juan, thank you for waiting until everyone has finished their work to sharpen your pencils."

When Susan came to the teacher's desk and interrupted Ms. Miller and Pete, who were working together on a special assignment, Ms. Miller and Pete paid no attention to her.

After several weeks of school, the class reviewed and finalized the guidelines about the behavior expected from each member. In addition to establishing a classroom code of conduct, they decided on some consequences for infractions of the rules.

While Steven was chewing gum in class, the teacher went to his desk and said to him quietly, "Don't chew gum at school, Steven."

During a group science activity, Bill was disruptive. His teacher had him return to his desk for 5 minutes while the others continued the science experiment.

Because Tyler was not absent for a week of school, he was allowed 10 minutes of extra gym time on Friday afternoon.

Emily became ineligible for this week's monitor duty because she was disruptive in the hall before school.

Susan earned the entire class 5 minutes of extra lunch time because she didn't argue with her teachers all morning.

Each student who returned to campus on time after lunch break for 2 school weeks is rewarded with bonus points toward their semester grade.

When the entire class was not disruptive during history period Monday through Thursday, the weekly history test was canceled. 


\begin{tabular}{ll}
\hline Tactic & Definition \\
\hline PEER MANAGEMENT & \\
Tutoring & One student proficient in an academic \\
& assignment serves in the role of teacher \\
& for a classmate who needs additional as- \\
sistance.
\end{tabular}

Behavioral managers

Environmental restructuring

\section{SELF-MANAGEMENT}

Self-regulation

Self-evaluation

Self-reinforcement

\section{PARENT ACTION}

Restitution

One whose classroom behavior is usually appropriate earns the privilege of becoming the dispenser of praise and rewards for a peer.

The class is instructed and reinforced for encouraging a classmate's appropriate behavior.

Individuals monitor their own behavior, seek to avoid those situations that precipitate inappropriate behavior, and stop that behavior if it is initiated.

Correcting one's own performance, recording the frequency, and graphing the resulting data.

Rewarding oneself for correct behavior.

Involves parents in the design and implementation of an intervention plan.

Extreme practice of the desired forms of the target behavior.

\section{Example}

Sally had difficulty learning her arithmetic facts and, therefore, was very disruptive during the time scheduled for arithmetic. Her teacher paired her with a classmate for extra drill and practice, which resulted in less disruption and Sally's mastery of arithmetic facts.

After training in behavioral techniques, Brian became the behavioral manager for Kevin. Brian modeled correct behavior and reinforced Kevin when he acted appropriately.

Franklin had a history of disturbing class during study and seatwork assignments. In the past, the class laughed at Franklin and encouraged his disruption. After discussion and training sessions, the class learned to praise his quiet working behavior and ignore his disruptions.

When Bill realized that he and Lonnie were about to begin to fight, Bill left the playground and returned to his classroom.

Judy marked each time she talked out during school on a score sheet kept on her desk. At the end of each day, she totaled the tallies and graphed the score.

Because Leroy did not get into trouble that day in the lunchroom, he stopped at a convenience store after school and treated himself to a soda.

Young-il's parents worked with his teacher to develop a plan to promote homework completion at home with reinforcement by the teacher.

Megin pushed and shoved her way into class after recess. For the next 5 school days, she had to hold the classroom door open for her classmates. This made her the last one returning to class after recess and lunch breaks.

In a mood of defiance, Gail tipped over her desk. As her consequence, she had to straighten the entire classroom. 
which can be very reinforcing to some youngsters. This tactic also often produces a "ripple effect" (i.e., other students engage in the behavior that was praised to earn their own praise from the teacher). Following are some ideas for implementing the specific praise intervention technique.

1. Identify the target behavior.

2. Provide a positive comment about the expected behavior.

3. Make the statement specific to the behavior.

4. Provide specific praise orally or in writing, publicly or privately depending upon the situation and the student.

5. Apply specific praise consistently and then intermittently.

6. Evaluate the effectiveness of the intervention frequently.

7. Develop a plan of how to increase the use of specific praise in the classroom.

8. Consider how the "ripple effect" and the use of specific praise could change students' behaviors.

\section{Ignoring}

Ignoring requires educators to systematically withdraw attention for every occurrence of the problem behavior. It can be a powerful intervention when used correctly in appropriate situations. For example, it is effective only when the person whose attention is being sought is the one who withholds attention. In the following example, ignoring Jim's talking behavior worked only when the attention of the students around him in study hall was withdrawn and he was aware of this situation.

Jim talked to several students around him during study hall. The study hall teacher chose to ignore Jim's disruption, but the behavior only worsened. When the teacher told the students privately that they were not to talk to Jim and when he realized that he was being ignored, Jim's disruptive behavior ceased.
Below are guidelines for the use of ignoring. Teachers must use discretion when ignoring behaviors (Sabatino, 1983). Some behaviors (e.g., tattling, whining) indeed can be ignored safely without risk to instruction. Other behaviors (e.g., throwing objects, hitting), however, can interfere with instruction or pose a threat to the student, teacher, or other students. In these cases, ignoring is obviously not the appropriate intervention to use.

1. Identify the behavior of concern.

2. Identify whose attention the student is seeking; that person should implement the intervention.

3. Ignore the student when the target behavior occurs.

4. Provide attention and praise to the student when the target behavior does not occur.

5. Use the "ripple effect" to obtain appropriate behavior.

6. Identify ways that nonverbal communication can be used as part of the ignoring technique.

7. Identify behavior problems where specific praise paired with ignoring would be effective interventions.

8. Consider ways to teach students to ignore the target student.

\section{Criterion-Specific Rewards}

Teachers can encourage discipline by implementing various reinforcement procedures. The use of criterion-specific rewards implies that the student earns a privilege only for reaching the desired level of the target behavior, such as increasing academic performance or decreasing inappropriate behaviors. Rewarding students for engaging in appropriate behavior is positive and most often successful. If reinforcement is used to reduce disruption, it should be used to improve academic performance as well. When implementing a

\section{TABLE 2 \\ Examples of Rewards}

\author{
Elementary-Level Students \\ Happy face stars and stickers \\ Student of the week \\ Super stars \\ Good work displayed on bulletin board \\ Puzzles and games \\ Choice of playground equipment \\ Assignment reduction \\ Principal's helper
}

\author{
Secondary-Level Students \\ Grades \\ Certificate of recognition \\ Honor roll club recognition at the end of each grading period \\ Bulletin board decoration \\ Age-appropriate board games \\ Library pass \\ Choice of seat \\ No homework
}


criterion-specific reward system, several considerations must be addressed: selecting reinforcers, establishing criterion for earning reinforcers, and identifying schedules of reinforcement.

Rewards selected for students do not have to be expensive or tangible, and the system for earning rewards does not need to be complicated. (See Table 2 for examples.) Simple systems are often more effective than complex ones. The following suggestions are offered for identifying reinforcers and rewards:

1. Determine the activities students prefer through observation and questioning.

2. Have a variety of age-appropriate reinforcers available to meet individual preferences and to provide options.

3. Try new rewards as student preferences change.

4. Select reinforcers that are inexpensive, are easy to locate and implement in the classroom, and can be enjoyed in a short amount of class time.

5. Schedule time daily or weekly for students to enjoy the earned reinforcers.

The criteria for earning a reward will vary. Criteria can often be determined from behavioral objectives, teacher's guides, or common sense. For example, most academic skills should be taught to mastery, which means from $85 \%$ to $95 \%$ accuracy. However, certain academic skills, such as counting money and telling time, should be taught to a $100 \%$ criterion level. Criteria for decreasing disruptive behavior also varies. Some behaviors (e.g., hitting, stealing) must be reduced to $0 \%$ occurrence, whereas others (e.g., out of seat, talking out) may be acceptable at just a few occurrences during a certain period of time. Criteria for decreasing or extinguishing inappropriate behavior can be determined from behavioral objectives, social skills programs, and experience.

The schedule of reinforcement used depends on the individual needs of the students. For example, some students need continuous reinforcement contingent on achieving the specified criterion for performance when they are first acquiring a new skill. Some students who have recently learned a skill still require reinforcement on an intermittent, unpredictable basis to maintain the criterion level.

\section{Interdependent Group Contingency}

A group contingency involves a reward being given to students based on the behavior of other students. An interdependent group contingency is when the class or group earns a reward when the entire class meets the established goal. That is, everyone must perform the behavior in order for all students to reap the benefit of the reward. In this intervention, the entire group either does or does not benefit from the actions of the group. In other words, all who participate in the appropriate or inappropriate activity participate in its consequences. Classic research (e.g., Barrish, Saunders, \& Wolf, 1969; Broden, Hall, Dunlap, \& Clark, 1970; Sulzbacher \& Houser, 1968) has demonstrated the efficacy of the interdependent group contingency to manage student behavior and establish an environment of discipline. Additionally, this technique has been recommended for use in cooperative learning teams to minimize disruptive group behavior (Maurer, 1988).

Interdependent group contingencies have several advantages. First, they can be used to manage student behavior in large- and small-group situations. Secondly, they work effectively with all age groups, including high school students, to foster improved academic or social performance. Third, interdependent group contingencies can be fun and result in effective discipline and management without the heavy atmosphere that a rule-laden environment can foster. Below are several ideas for implementing this intervention technique.

1. Identify a target behavior maintained by the group.

2. Determine implementation details (e.g., game-like format, points).

3. Identify the criterion level and a reward.

4. Establish the reward schedule.

5. Tell students that to earn the reward everyone is accountable for the target behavior.

6. Collect data to determine the success of the interdependent group contingency.

7. Think of ways an interdependent group contingency can be implemented schoolwide by faculty working together to eliminate problems.

\section{Peer Management: Peer Tutoring}

Whether in the general or in the special education setting, students can be a very valuable resource in attaining academic and social skills. Peer tutoring implies that students proficient in certain academic skills assist other students who need additional help. This technique can be useful in meeting individual needs of students with disabilities, promoting academic achievement, and thus diminishing disruptive behavior. Peer tutors are beneficial in several situations: (a) working together to finish tasks; (b) assisting other students when the teacher is involved with small-group instruction; (c) serving as group leaders at learning centers, in committees, and in the library; and (d) helping other students who require assis- 
tance (Evertson et al., 1984). Once the decision has been made to institute a peer tutoring program in the classroom, teachers must address several considerations. Smith and Rivera (1993) offer the following guidelines for establishing a peer tutoring program.

\section{Guidelines for Tutoring Situations}

Regardless of the tutoring assignment a student is given (academic tutor or behavioral manager), some important factors relating directly to the success of tutoring situations must be included:

1. Select the tutors carefully. Select students who want to engage in tutoring relationships and have a good command of the content to be taught. Also be sure there is a good match between tutors and tutees.

2. Train the tutors. Tutors must receive instruction in effective techniques to impart subject matter, to manage behavior, and to reinforce the tutee. Teacher modeling and tutor role-playing can be used in practice situations to help tutors acquire effective techniques for working with tutees.

3. Provide incentives and rewards for tutors. Students selected as tutors may be motivated and inspired at the onset of the tutoring experience and then lose interest. Tutors must be provided with reinforcement for doing their job successfully.

\section{EVALUATION}

We have described a number of proven intervention procedures for modifying disruptive and disobedient behavior, but these strategies are not always effective with all children all of the time. We advocate the use of tactics lower on the Intervention Ladder first and the application of more stringent procedures only when less intrusive techniques are not sufficient to change the target behavior to meet the requirements of desired school and classroom deportment. Educators need to use evaluation procedures that provide immediate feedback about the influence of the tactics applied. Therefore, we suggest that evaluation be concurrent with the implementation of intervention techniques. The evaluation methods discussed here are simple but powerful enough for the purposes of judging the effectiveness of intervention procedures and communicating those effects to others. For those unfamiliar with plotting student data, numerous sources of information are available, but see especially Cooper, Heron, and Heward (1987) and Gardner et al. (1994).

\section{What Should Be Measured?}

The behaviors of primary concern should be the targets of the measurement. Measurement should center directly on the behavior the educator seeks to change. That behavior must be defined carefully and in observable terms. It must be something that can be consistently observed over a period of time. Moods, feelings, and self-concepts are very difficult to measure this way, but the ways in which they are manifested are not difficult to measure. A child might be called "moody," but when that child verbally assaults her classmates and teachers, swears at classmates, or announces that she will not do her work or follow classroom rules, measurement is an easy task.

Identification of the target behavior(s) can be easily accomplished by informal observations and anecdotal record keeping. Notes about what specific behaviors comprise disobedient acts can be very helpful in determining exactly what behaviors need remediation. During this observation period, many teachers often find that the behaviors of concern are neither as pervasive, general, or unmanageable as they had thought. This identification period must be complete. Its main purpose is to identify what is to be measured. If the teacher changes his or her mind in the middle of the evaluation phase, the data gathered become useless. One key to successful evaluation is consistency in what behaviors are measured and the strategy scheduled. Thus, to determine what to measure:

1. Select a behavior of great concern (e.g., causing destruction, interfering with instruction, hurting self or another student).

2. Define precisely the behavior to be measured (i.e., must be observable, countable, and have a beginning and end).

3. Observe consistently over a period of time (i.e., observe the same time each day for the same amount of time).

\section{How Should Behavior Be Measured?}

Behavior should be measured in the simplest way possible and with as much immediacy as possible. Evaluations of intervention programs should not become terribly complex. Evaluation of a behavioral intervention is not inherently better because it took hours to complete and involved an unwieldy measurement system requiring outside data takers. Often a simpler system results in easier application and communication.

Once the behavior or set of behaviors targeted for remediation are identified precisely, the teacher must decide what measurement system to use. The measurement system to be selected depends on the type of behavior change desired (e.g., 
Is the teacher concerned with the frequency or with the duration of the behavior?). The amount or frequency of the following behaviors is usually what constitutes the problem: littering on school grounds, defacing or destroying property, talking back to the teacher, not completing homework or seatwork assignments, or not returning library books. However, for some behaviors teachers are more concerned about the duration of the target behavior: for example, the amount of time wasted during class or spent changing from class to class or activity to another activity, preparing to leave school at the end of the day, or coming from the school bus to the classroom.

In some cases, both the frequency and duration of the behavior can be of concern. In these situations the educator should decide which aspect is more important (or take both frequency and duration data concurrently). Although often related, the frequency and duration of behaviors are not necessarily dependent on each other. For example, a student can be out of his or her seat once, but for the entire class period. Thus, when determining how to measure behavior: (a) use the simplest technique and (b) select a system that is sensitive to the target behavior.

\section{When Should Behavior Be Measured?}

Behavior should be measured in the same way and at the same time each day the teacher and student work together. The notion of consistent and daily (or very frequent) applications of tactics and measurement systems is critical to successful intervention. The purpose of collecting precise information about student performance is to determine whether the infraction is serious and whether the scheduled intervention causes the desired improvement. To judge the effectiveness of the intervention, the teacher must be able to compare one day's performance with another and one week's performance with the next. For this to occur, the measures of the target behavior must be equivalent. They must be taken frequently (preferably daily) on the same behavior or set of behaviors with the same measurement system under similar conditions. Frequent measurements provide a more accurate and complete picture of the student's behavior patterns. Teachers need to know as soon as possible whether the initiated programs are producing the intended results, particularly for serious infractions. Pre- and posttesting with several months between each evaluation is a luxury educators and school environments cannot afford. Also, subsequent educational planning is best when information is readily available. When deciding when behavior should be measured:
1. Use the measurement the same way and same time each day.

2. Select a consistent time daily to measure the behavior.

3. Compare the data from one day and week to the next.

4. Measure frequently, preferably daily.

\section{Who Should Conduct the Measurement?}

The school day is filled with many noninstructional tasks, and teachers' time is consumed with activities that limit their abilities to concentrate on instruction. The elimination or reduction of various behavioral distractions results in increased instructional time; however, it is not necessary for only teachers to spend time collecting information about student deportment.

There is no mystique about measuring student performance or collecting data on students' school behavior. Once the target behavior has been identified, the proper measurement system selected, and the time period for measurement determined, the collection and display of the evaluation data are relatively simple tasks. With some initial guidance and periodic monitoring, practically anyone can be assigned the task of collecting the data on which evaluation decisions will be made. Both experience and research indicate that people other than teachers-parent volunteers, para-educators, the targeted students, other students - can collect accurate information. If students are used, however, they might initially need assistance so they will be neither too stringent nor too lenient.

\section{Measurement Systems}

Many different measurement systems are available for evaluating the effectiveness of intervention procedures on the improvement of student performance. Some of these (e.g., correct and error rate scores, percentage correct scores) are more applicable to instructional situations; others are more complicated than necessary for most instructional or discipline situations. Simple data collection systems usually meet the need. In particular, three measurement systems are most useful to assess student deportment: frequency, duration, and the percentage of those two indicators of performance.

Frequency indicates how many times the student engaged in the target behavior. It is a tally or count of the number of times the behavior occurred over a constant period of time or of how many students engaged in the target behavior.

Duration data answer the question "How much time did the student engage in a certain activity?" The person collecting the data should be given a stopwatch that can accumulate 
time. Each time the targeted behavior begins, the stopwatch is started, and each time the episode concludes, the stopwatch is stopped. At the end of the period, the total amount of time spent engaged in the target behavior appears on the face of the stopwatch, and that becomes the day's data to record. When this method of collecting duration data is used, the teacher knows only the total time the student engaged in the undesirable behavior for the observation period, not how long each episode lasted. Since, however, the major concern usually is the total amount of instructional time being misused, information about the time involved for each occurrence of the target behavior during the period is not as important.

In middle and high schools, academic periods last for fairly consistent lengths of time. On the rare days when the schedule is altered, those data could be discounted and not entered into the permanent record. Tardiness is usually observed under constant conditions, and simple duration data are sufficient for the purposes of daily and weekly comparisons. In elementary schools, teachers usually schedule their school day according to a constant set of time periods. Some keep records of school deportment for the entire school day. In these cases simple frequency and duration data suffice.

Percentage of occurrence is a type of measurement system that adjusts for observation times that are not consistent. As just mentioned, if frequency or duration data are collected, the time period for data collection must be constant since the purpose of data collection and the application of a measurement system is for a comparison of one day's data with another. In many school situations, observation times cannot be consistent. Many factors contribute to this problem, including abbreviated school days and inconsistent class periods. When consistent observation times are not possible on a daily basis, simple frequency and duration data are not useful without an additional calculation turning the raw data into percentage scores.

\section{Evaluation Phases}

Four basic phases comprise most behavioral evaluation plans: assessment, intervention, maintenance, and follow-up. The assessment phase has many obvious purposes: identification of the seriousness of the infraction, the intensity of its occurrence, and the conditions under which it occurs. Consistent daily assessment before interventions are scheduled has many benefits. Often the teacher finds that the correct behavior for change has not been identified and other behaviors need to be identified and measured precisely. Sometimes the seriousness of the problem leads to selection of a procedure higher on the Intervention Ladder than originally planned. Of course, the primary benefit of the assessment phase is for later comparisons. Only when teachers know the original levels of the behavior under consideration can an evaluation of long- and short-term effects be made.

The intervention phase follows the assessment or baseline period. The intervention selected should be in effect each observation day during this phase. After several days of explaining the intervention strategy to the students, daily instructions are not necessary. The intervention phase should last as long as necessary. There are two fundamental reasons for terminating an intervention: either a criterion has been met or the intervention is unsuccessful. Data should guide teachers making such determinations. Sometimes an intervention is effective initially but loses its power with time. When the evaluation data indicate that this has occurred, another intervention strategy should be planned that adds to or replaces the first. Unfortunately, not all interventions work as hoped or expected. If evaluation data indicate that the behavior worsened or that the intervention did not produce the desired results, another plan must be put into effect. Therefore, many remediation programs include more than one intervention phase.

When interventions are terminated, the previous undesirable behavior patterns may return. Thus, it is necessary to implement a maintenance phase by continuing to measure the target behavior after the intervention phase is concluded. For several weeks the teacher in charge of the project should continue measurement of the target behavior according to the schedule followed during the assessment and intervention conditions. If the desired deportment is maintained, then periodic checks should ensue in a follow-up phase.

When designing an intervention plan for a targeted behavior, remember to:

1. Conduct an assessment phase (baseline) to obtain information about initial performance.

2. Select a measurement system that is sensitive to the targeted behavior.

3. Measure daily at the same time.

4. Graph and utilize decision rules.

5. Implement the intervention systematically and on a daily basis.

6. Establish a criterion for mastery.

7. Compare assessment with intervention phase data to determine if progress is being made.

8. Conduct periodic checks to assure maintenance.

9. If students don't maintain their performance, intervene immediately and consistently so data can guide decision making.

10. Match infraction and intervention using data collected. 


\section{Displaying Data}

For ease of analysis and communication with other educators, the school community, parents, and students, the display of the evaluation data need not be complicated. Graphs do not have to be constructed or maintained only by the adult supervising the intervention project. Students can contribute to this task while applying the basic mathematics skill of graphing. A disruptive student could earn the privilege of keeping a class graph for a period of time, or a responsible student can be assigned the task. Students whose behavior has been targeted for remediation could chart the evaluation data gathered on themselves. Although not terribly time-consuming, constructing and keeping graphs current can be one more unnecessary task to ask teachers and other school personnel to assume. Therefore, whenever possible, consider asking students to construct and enter the data on the graphs.

\section{CONCLUSION}

With recent calls for more inclusive schools (NASBE, 1992; Sailor, 1991), general education teachers are seeing a higher rate of integration of students with disabilities in their classrooms. One result is a greater diversity of ability, motivation, skills, and achievement. A frequent by-product of such diversity is higher levels of disruption, which, unfortunately, can negatively impact the learning environment. All teachers, and particularly those working in inclusive classrooms, must work diligently to ensure that students receive as much instructional time as possible. Without direct attention to this factor, positive instructional time can drop to extremely low levels (Pemberton, 1994) and negatively influence students' academic achievements.

High levels of disruption can alter the positive learning environment, remove the teacher from instruction, and result in classroom chaos. In this article, we suggest that discipline intervention can and should be helpful. Teachers must create learning environments that prevent and deter disruption. They must be armed with a wide array of interventions ranging from mild to severe and subtle to intrusive. When administered in a systematic and hierarchical fashion, intervention can result in an exciting situation where students are free to explore and learn to their levels of ability. We hope that this brief exploration of the context of discipline, the creation of positive learning environments, and the Intervention Ladder will assist you in developing a rich classroom where discipline is not a concern.

\section{REFERENCES}

Barrish, H. H., Saunders, M., \& Wolf, M. M. (1969). Good behavior game: Effects of individual contingencies for group consequence on disruptive behavior in a classroom. Journal of Applied Behavior Analysis, 2, 119-124.

Broden, M., Hall, R. V., Dunlap, A., \& Clark, R. (1970). Effects of teacher attention and a token reinforcement system in a junior high school special education class. Exceptional Children, 36, 341-349.

Center, D. B., Deitz, S. M., \& Kaufman, M. E. (1982). Student ability, task difficulty, and inappropriate classroom behavior: A study of children with behavior disorders. Behavior Modification, 6, 355-374.

Cooper, J. O., Heron, T. E., \& Heward, W. L. (1987). Applied behavior analysis. Columbus, OH: Merrill.

Evertson, C. M., Emmer, E. T., Clements, B. S., Sanford, J. P., \& Worsham, M. E. (1984). Classroom management for elementary teachers. Englewood Cliffs, NJ: Prentice Hall.

Gallup, A. M. (1984). The Gallup poll of teachers' attitudes toward the public schools. Phi Delta Kappan, 65, 97-107.

Gallup, A. M. (1994). Results of the Annual Gallup Poll. Lincoln, NE: Gallup Organization.

Gardner, R., et al. (1994). Behavior analysis in education: Focus on measurably superior instruction. Pacific Grove, CA: Brooks/Cole.

Kounin, J. S. (1970). Discipline and group management in classrooms. NY: Holt, Rhinehart, \& Winston.

Krumboltz, J. D., \& Krumboltz, H. B. (1972). Changing children's behavior. Englewood Cliffs, NJ: Prentice Hall.

Maurer, R. (1988). Special education discipline handbook. West Nyack, NY: Center for Applied Research in Education.

National Association of School Boards of Education (NASBE). (1992). Winners all. Alexandria, VA: NASBE.

Pemberton, J. (1994). An analysis of teacher time during the school day: A study comparing five service delivery models available to students identified as having disabilties. University of New Mexico: Unpublished doctoral dissertation.

Sabatino, A. (1983). Prevention: Teachers' attitude and adaptive behaviorSuggested techniques. In D. A. Sabatino, A. C. Sabatino, \& L. Mann (Eds.), Discipline and behavioral management (pp. 29-84). Austin, TX: PRO-ED.

Sailor, W. (1991). Special education in the restructured school. Remedial and Special Education, 12, 8-22.

Smith, D. D., \& Rivera, D. M. (1993). Effective discipline. Austin, TX: PROED.

Sulzbacher, S. I., \& Houser, J. E. (1968). A tactic to eliminate disruptive behaviors in the classroom: Group contingent consequences. American Journal of Mental Deficiency, 73, 88-90.

Windell, J. (1991). Discipline: A source of 50 fail-safe techniques for parents. New York: Macmillan.

PERMISSIONS AND COPYRIGHT • All rights are reserved. No part of this publication may be reproduced, photocopied, faxed, stored in a retrieval system, or transmitted, in any form or by any means, electronic, mechanical, recording or otherwise, without the prior written permission of the publisher. $\bullet$ Back issues are available for sale. $\bullet$ Reproduction requires permission and payment of fees. It is illegal and a violation of federal copyright law to reproduce this publication without permission. Direct all inquiries to the permissions editor. 


\title{
Teaching Special Learners in the General Education Classroom
}

\section{Methods and Techniques-Second Edition}

\author{
Kathleen McCoy \\ Arizona State University
}

\begin{abstract}
Responsive to supporting the inclusion of special students in the general education classroom, this second edition of a popular book for teaching special children in the general education classroom helps teachers understand children with disabilities and provides effective instructional strategies. Packed with ideas for managing and organizing classroom time, it includes instructional tips and suggestions. Multicultural concerns and technology are addressed in a way that helps teachers get the job done for the maximum benefit of all the children.
\end{abstract}

\section{Features}

- Covers planning, assessment, and groups

- Addresses all of the inclusion issues

- Shows intervention methods and techniques

- Presents vignettes to personalize each situation
- Responds to all sides of the major issues

- This book has personality and will appeal to the general education classroom teacher

- Glossary

\section{Contents}

1. A Modern Fable

2. Mainstreaming and Inclusion Movements

3. Children with Mild to Moderate Learning Problems

4. Children with Physical, Visual, and Hearing Disabilities

5. The Individualized Education Program

6. Classroom Organization

7. Pinpointing Reading Skills

8. Reading Methods
9. Reading for Special Populations

10. Language Arts Stephen Isaacson

11. Mathematics Skills Evaluation

12. Mathematics Instruction Virginia Usnick and Kathleen McCoy

13. Accommodation Through Technology: Personal Computers

\section{LOVE PUBLISHING COMPANY}

\author{
1777 South Bellaire Street \\ Denver, CO 80222
}

303-757-2579•Fax 303-782-5683 


\section{professional update}

\section{March 1-4, 1995}

Learning Disabilities Association of America

Twin Towers Hotel and Resort

Orlando, FL

Contact: LDA 1995 Conference

4156 Library Rd.

Pittsburgh, PA 15234-1349

\section{March 21-25, 1995}

National Association of School Psychologists Chicago Hilton Hotel

Contact: National Association of School Psychologists 8455 Colesville Rd., Suite 1000

Silver Spring, MD 20910

\section{April 5-9, 1995}

CEC Annual Conference

Indiana Convention Center, Indianapolis

Contact: Council for Exceptional Children 1920 Association Drive

Reston, VA 22091
April 10-13, 1995

Fourth International Special Education Congress

Birmingham, England

Contact: John Visser

School of Education

University of Birmingham

Birmingham B15 2TT

England

FAX 021-414-4865

April 18-22, 1995

American Educational Research Association

San Francisco Hilton Hotel

Contact: American Educational Research Association 1230 17th Street, NW

Washington, DC 20036 